\title{
Talking about Problems and Countermeasures of Small-sized
}

\section{Apartments Design}

\author{
Wenye Gong ${ }^{1,}$, Tianwei Bai ${ }^{2, b}$ and Donglin $\mathrm{He}^{3, \mathrm{c}}$ \\ ${ }^{1}$ North China University of Water resources and Electric Power, Zhengzhou, 450046, China \\ ${ }^{2}$ Jilin University, Changchun, 130012, China \\ ${ }^{2}$ University of Illinois at Chicago, Chicago, Illinois, USA \\ ${ }^{3}$ Kaifeng University, Kaifeng, 475000, China

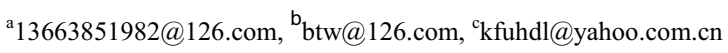

\begin{abstract}
In order to promote the healthy development for small apartments, the author made a full investigation to Zhengzhou of China, analyzed the existing problems of small-sized houses, and proposed improvement suggestions from traffic space, family-unit design and plan-combination. These measures will help to create a suitable living environment for users.
\end{abstract}

Keywords. Small-sized apartment, traffic space, house type, plan combination

\section{Introduction}

With the rapid development of the national economy, the improvement of the consumption and the prosperity of the market, the real estate sales are full of competition. Due to less investment, low down-payment and high rent returns, the small-sized apartment is nearly the favourite house for young people and most investors. What about the quality of the small apartment? Take Zhengzhou City of Henan province as an example, there are obvious shortcomings and defects in the daily use according to spot investigations. For instance, high density will lead to traffic congestion, monotonous house-type will cause the use-inconvenience, and the space of over saturation will give a non-communication environment to residents. How to do a small-apartment design? How to achieve "small but complete" and "dense but comfortable"? This paper mainly discusses the improvement measures of small apartments from the aspects of traffic space, house-type design and plan combination, which to create a suitable habitat environment and promote sound development of small-sized apartments.

\section{Present situation of small-sized apartments}

In general, small-sized apartments are given characteristics as surrounding by convenient traffic, locating in the downtown of the city and having a perfect life support. The advantage of low price can satisfy people's ideal of urban life. Today, in the fast-paced city environment of high housing prices, small apartments play an important role in solving the housing needs of low-income families and saving land resources.

In Zhengzhou, for example, with a recovering housing market since 2015, sales volume of small-sized apartments have accounted for about $60 \%$ of the total. Small dwelling house can be divided into two kinds according to the size of the area. One kind is absolute small-house with $20 \sim 30 \mathrm{~m}^{2}$, some having hall and some having not, such as Changsheng Square, Longzihu Micro-era and Yingzuo Square. The other kind is relative small-house of $40 \sim 50 \mathrm{~m}^{2}$, which can be designed into "one hall+ one room + one toilet" or "one hall+ two rooms + one toilet", and characterized by compact 
housing space. For example, Meijing City, Qihuihao Home and International City, which living-room area is not more than $20 \mathrm{~m}^{2}$ and the bedroom is not more than $10 \mathrm{~m}^{2}$.

\section{Problems in small-sized apartments}

High density leads to traffic congestion. With the rising price of land, the construction of high-rise buildings is undoubtedly the best choice for estate businessmen, so that existing small apartments are mostly high-rise buildings relying on elevators to achieve vertical transportation. Zhengzhou as an example, in International City community, the first-stage project has 12 floors, the second-stage is 18 and the third is built to 26 stories, which accommodate thousands of families. Similarly, Yinzuo Square plan a new concept of small-family, composed of two blocks of 30 stories business-living buildings, which 1-4 floors are shops and 5-30 floors for dwelling houses, all composed of 36-59 $\mathrm{m}^{2}$ small-sized apartments,[1] so the living density is high. Residents in small-apartments are mostly young people with frequent activities, which hundreds of people go in and go out in the rush hours. On average, each elevator will carry 100-200 households every day, so the waiting time and crowded degree can be imagined. If the power-outage occurs, people must be in an awkward situation of "can't go up and can't get down".

Duplicate design of dwelling unit leads to the use of inconvenience. At present, small-sized apartments in Zhengzhou are mostly one-room type like standard-room of the hotel, there is no natural ventilation and only one side has natural light. Common unit-types in the market are shown in figure.1. The merger of living-room and bedroom led to having no daily reception space, balcony or corridor is usually occupied for cooking space, and the lack of storage space generally exists.[2] Monotonous apartment design cause a long and narrow "gray space". The bedroom is too bright and the living room is too dark, which is not conformed to people's living habits. As shown in figure.2, $30 \mathrm{~m}^{2}-40 \mathrm{~m}^{2}-50 \mathrm{~m}^{2}-60 \mathrm{~m}^{2}$ are all simply designed into one room, which unreasonable design is obvious.

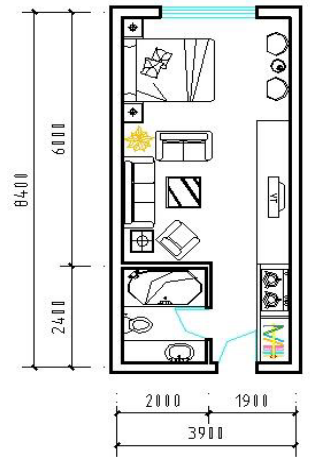

Fig.1. The one-room house type of small apartment

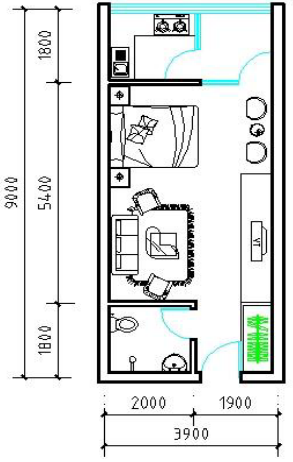

(1)

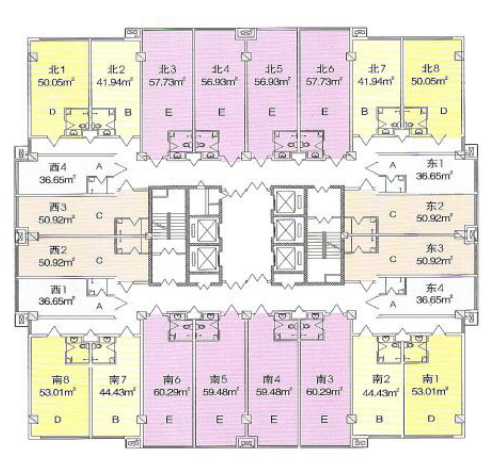

Fig.2. The plan of Yinzuo Square

Too compact plan-combination causes the loss of communication. In recent years, with the increasing floors of high-rise buildings, the communication between the neighbourhoods has been greatly reduced. Real estate developers often require an airtight design in order to seek maximum benefits. Apart from long-narrow aisles and cramped elevator lobbies, no space can be used to carry out public interaction. Buildings in this design ideal will inevitably lead to the deterioration of the living environment and indifference of neighbourhood relations. At the same time, each layer accommodated a large number of households, which has resulted a complicated and large- interference environment. The residents are not familiar with each other, which will lead to the occurrence of many unsafe incidents in a way. Moreover, hundreds of household-doors in building are decorated as a unified style without any sign, easy to make people lost direction.

\section{Discussion on the design strategy of small-sized apartments}


Increase the number of lifts and the width of corridors to ease traffic. Buildings of small-sized apartment mainly locate in three areas: one is downtown of bustling cities, the other is close to the city's main traffic lines, and the third is working areas of young men.[3] In these regions, the rent is higher and the demand for small apartments is larger. Therefore, the developers want to build houses as much as possible. In high-density buildings, if designers increase the width of corridors and the number of elevators appropriately, traffic pressure will be reduced. For example, if the aisle be widened from $2.4 \mathrm{~m}$ to $2.7 \mathrm{~m}$, and service-number of each elevator be reduced from 5-6 to 3-4 households, (figue.3) traffic efficiency will be greatly improved. At the same time, the partition service of lifts can reduce the waiting and running time to relieve the anxiety.
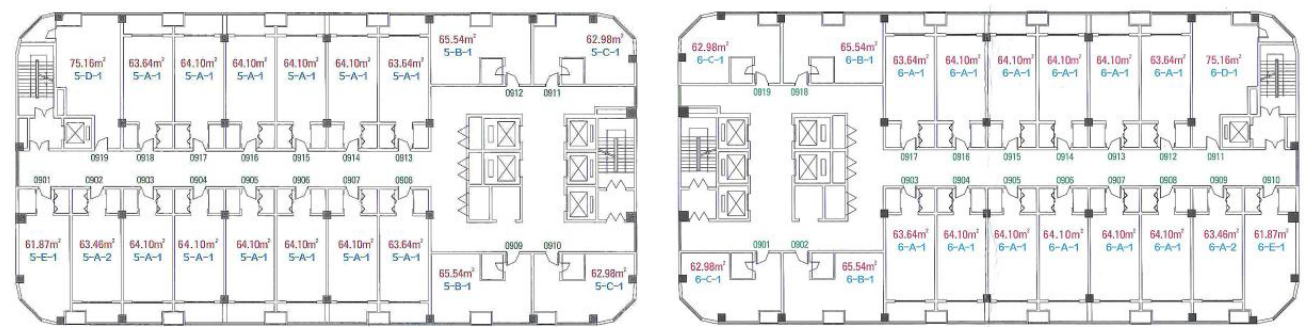

Fig. 3. Building5 and building6 of Changsheng Square of Zhengzhou

Try the diversified design of house-type to meet the use requirements. As stated earlier, the monotonous design of small houses directly leads to unreasonable rooms and poor living function. If designers increase face-width of each household appropriately in the premise of land-saving, and change vertical flat into horizontal flat, (figure 4) many problems can be avoided.[4] As shown in figure 5, if the span is widened to $5.4 \mathrm{~m}$ and the surface is recessed into a small piece, the bedroom and living room can be intersected. In this way, designers can not only effectively control the area, but also open more windows to achieve natural lighting for living room, bedroom and kitchen. Another example is shown in figure 5, two households sharing $1.8 \mathrm{~m}$-width kitchen and toilet space, all spaces such as reception, rest and cooking play their proper roles, [5] which can improve the living quality greatly.
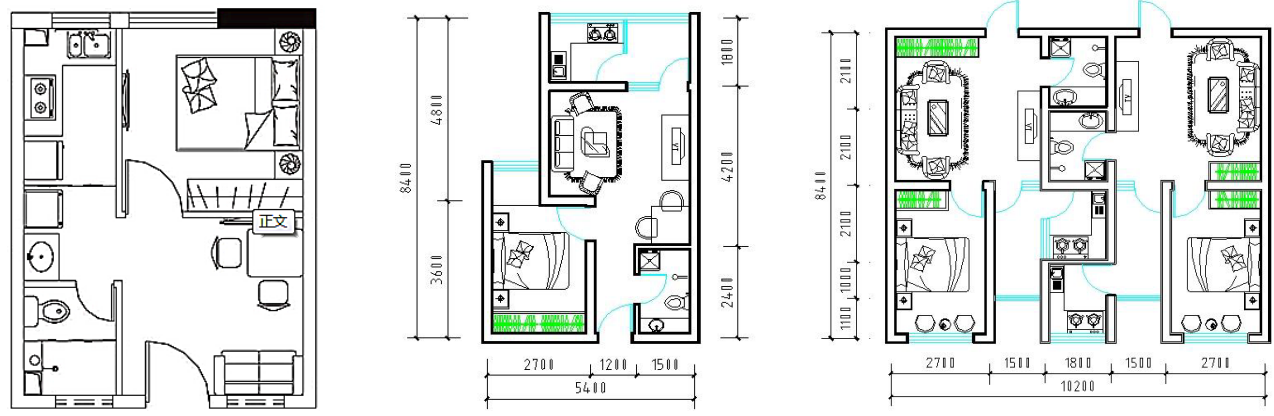

Fig.4. The horizontal flat

Fig.5. The combination design of horizontal flat

Try the diversified design of plan-combination to promote neighbourhood communication. House is the place where people live every day, so it must be humanized. It should meet people's life needs in physiology and psychology. In the view of physiology, although the area is limited, small apartments should have complete function and natural lighting. From the angle of psychology, in addition to privacy requirements, small-sized house should consider people's communication needs. As shown in figure 6, some concave-processing of building-plane can achieve the nature lighting and ventilation for small-sized apartments. [6] At the same time, designers set aside some wide concave corridors or verandas in the plan nod, which can be properly set up seats or green plants to form a small hanging garden [7] to provide conditions for the communication between the neighbours. These measures will help to improve the neighbourhood relationship in high density environment, enhance people's familiarity and establish a sense of responsibility. Of course, the establishment of public space is a common thing of their neighbouring residents, the 
increasing of shared area will aggravate the economic burden, so it is necessary to conduct a thorough discussion and extensive publicity in the planning and design stages.

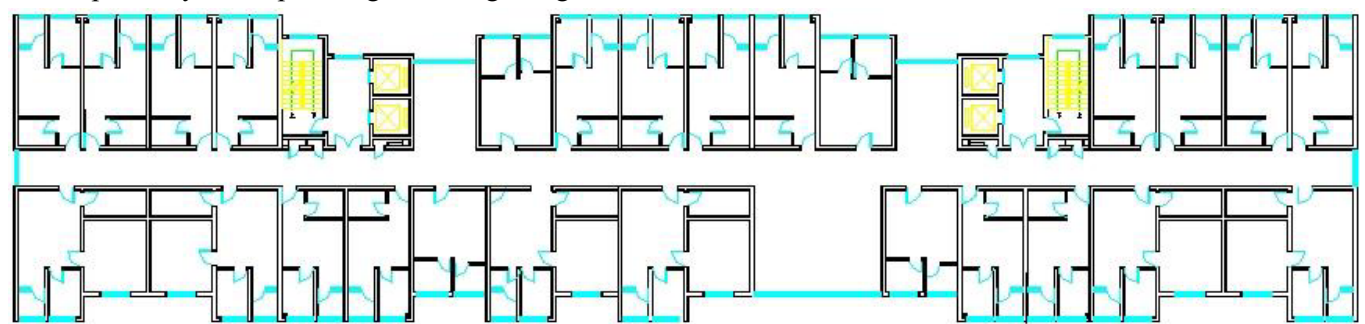

Fig. 6. The plan-combination of small apartments with concave corridors

\section{Conclusions}

With the flow and aggregation of urban population, the demand for small houses will increase, and the market share will be high more and more. The optimized design of traffic space, family-unit and plan-combination can improve the quality of small apartments. In addition, perfect infrastructure and high-level property management will also play an important role in elevating the living environment for residents.

\section{References}

1. Information on http://www. newhouse.zz.fang.com

2. Y. Tian: Creative Design of the Space of Small Apartment (China Building Industry Press, Beijing 2010).

3. L. Hong and J.T. Ying: Research on Small-sized Apartments in Modern Buildings. Jiangxi Building Material. Vol. 13 (2014), p. 24

4. S.F. Lu, L. Zhang and J. Zhou: Introduction to design plan of small family houses. Housing Science, Vol. 12 (2013), p.19-22

5. Y. Jiang: The sustainable development of small and medium sized unit. Architectural Journal. Vol.11 (2007), p.19-22

6. H. Chen, YH. Lv and Q. Ji: Middle and small family housing flexibility and variable designing. Chinese \& overseas architecture. Vol.4(2007), p.13-15

7. J. Choi and T. Cho: Comparing Perception Concerning the Importance of Apartment Complex Components between Consumers and Housing Providers. Journal of Asian Architecture and Building Engineering. Vol.1(2014), p.109-116 